\title{
Synergistic Effect of Integrated Project Delivery, Lean Construction, and Building Information Modeling on Project Performance Measures: A Quantitative and Qualitative Analysis
}

\author{
Phuong Nguyen ${ }^{1}$ and Reza Akhavian (D) $^{2}$ \\ ${ }^{1}$ Department of Civil, Environmental and Architectural Engineering, University of Kansas, 1530 W. $15^{\text {th }}$ Street, \\ 2150 Learned Hall, Lawrence, KS 66045, USA \\ ${ }^{2}$ School of Engineering, California State University, East Bay, 25800 Carlos Bee Blvd, Hayward, CA 94542, USA \\ Correspondence should be addressed to Reza Akhavian; reza.akhavian@csueastbay.edu
}

Received 21 January 2019; Revised 19 April 2019; Accepted 23 June 2019; Published 1 July 2019

Guest Editor: Tatjana Vilutiene

Copyright (c) 2019 Phuong Nguyen and Reza Akhavian. This is an open access article distributed under the Creative Commons Attribution License, which permits unrestricted use, distribution, and reproduction in any medium, provided the original work is properly cited.

\begin{abstract}
In the recent years, owners and construction management companies have shown an increasingly more interest in adopting approaches that result in enhanced quality and less risks, conflicts, and wastes on their projects despite potentially higher initial cost. Implementing advanced technology trends and incorporating more integrated methods of delivering projects have proven to be highly value-adding and forward-thinking approaches. The objective of this research was to evaluate the effectiveness of and the synergy between three of such trending concepts in the construction industry, namely, integrated project delivery (IPD), lean principles, and building information modeling (BIM) in terms of cost and schedule performance measures. Data analysis was conducted on 72 vertical projects through interviews and study of the published articles, reports, and case studies. Qualitative analysis was performed through grounded theory while quantitative analysis was implemented using univariate and multivariate analysis of variance tests on schedule performance and cost performance. Results of the grounded theory analysis summarize six crucial characteristics required for an effective coordination between IPD, lean construction, and BIM. Statistical analysis on different combination of these three components revealed considerable effectiveness in terms of schedule performance while the effect on cost performance was not as much significant. This study contributes to the body of knowledge and practice in the field of construction by demonstrating the cost and schedule benefits realized through the use of IPD, lean construction, and BIM and identifying their collective conceptual advantages.
\end{abstract}

\section{Introduction}

The US construction industry experienced $6 \%$ performance (approximately $\$ 712$ billion) in value and achieved 13\% increase in the financial profit in 2016 [1]. It is predicted that construction industry's value will be consistently growing with the advancement of modern technologies and adoption of integrated approaches to improve construction performance measures [2]. Construction project cost and schedule are difficult to predict accurately due to complexity of procedures and the presence of various uncertain variables throughout a project. As a result, forecasting and envisioning project cost and schedule performance measures are complicated even for experienced construction experts and professionals [2]. As such, many researchers have been trying to find and recommend the factors that can influence project cost and schedule in a positive way. Many such recommendations are proposed to improve project quality, reducing total costs and time to build, and achieving the most desirable value. Furthermore, regardless of the project delivery method, construction project owners show significantly increased interest in employing technology trends such as building information modeling (BIM), sensor-based resources tracking, automation and robotics, and machine learning [3-5]. In addition to the technological advancement, the industry has come to a general agreement on the 
value of implementing lean principles while benefiting from the advantages of early coordination and communication between project parties [6]. The latter, has commonly characterized itself via a trending project delivery method, the integrated project delivery (IPD). In the US construction industry, use of IPD necessitates benefiting from advanced techniques including BIM and lean practices [7, 8]. In IPD projects, members meet regularly in early stages of the project initiation where they deliberately discuss relevant issues and practically streamline critical tasks related to the design and construction stages [9]. Not only do such methodologies guarantee lower number of changes and higher levels of confidence in adhering to the original project budget and duration estimate, they also tend to result in more sustainable and resilient outcomes. The motivating questions of this study are as follows:

(1) How can the three components, IPD, BIM, and lean construction be efficiently used in construction projects?

(2) What are cost and schedule implications of projects that utilized a combined framework of IPD, BIM, and lean construction?

This research study aims to investigate the cooperative relationship and efficiency of different combinations of IPD, lean construction, and BIM in improving the performance of construction projects in the U.S. construction industry. Towards this goal, the efficiency of construction projects benefiting from integrated frameworks including different combinations of IPD, lean principles, and BIM (ILB in short hereinafter) is explored in 72 vertical construction projects and case studies. Qualitative and quantitative analyses were employed to evaluate the projects' cost and schedule performance. Three key phases of a construction project, namely, preconstruction (planning, predesign, estimating costs, schematic design, and constructability review), construction (managing constructing process, tracking project schedule, and controlling costs), and postconstruction (project closeout work and completion) are specifically investigated using the proposed evaluation model.

\section{Literature Review}

A number of recent research studies have discussed the use of IPD, lean construction, and BIM in the US construction industry while there are few projects focusing on investigating the mixed use of all IPD, lean principles, and BIM in terms of project performance metrics, such as cost and schedule performance. In this section, the definition of each component of the ILB integration as described in the construction literature is provided and then the recent research concentrating on the use of all three components in projects are discussed.

2.1. Integrated Project Delivery. According to the American Institute of Architects (AIA), IPD is an important concept in the modern construction that brings together people to examine different building systems through various means of business practices in a collaborative environment [9]. It provides two contractual conceptions: multiparty agreements (MPA) and single purpose entity (SPE) [10]. These concepts refer to the equal distribution of risks and rewards of project-involved parties and requiring an early participation of all involved parties $[7,11]$. The main purpose of IPD is to resolve several considerable weaknesses of common project delivery methods such as unassured productivity levels, deficiencies in managing schedule and budget, inadequate information in specifications and drawings, and high level of materials' wastage [12].

2.2. Lean Construction. In the $1990 \mathrm{~s}$, recognized as an outcome of the Toyota Production System (TPS), lean manufacturing (or lean production) was established and executed with significant achievements that led to the original uses of lean thinking in the construction industry [13-15]. Since lean principles were originally appeared as a philosophy, it can be defined in many different ways in accordance with the purpose of the users [16-18]. Lean in construction is described as a method to design a construction system to immensely lessen waste of time, materials, and effort in the interest of maximizing possible project value $[19,20]$. Lean thinking concentrates on identifying and setting up expected targets and attempts to streamline the master plan. Transforming from lean production, there are three unique concepts of lean principles that construction professionals have identified and evolved: the last planner system, target value design, and lean project delivery system $[17,21-23]$. In addition, a variety of means and techniques related to these three concepts are utilized in the construction industry, such as integrated lean project delivery (ILPD), A3 report, lean process design, just-in-time and offsite fabrication, value stream mapping, visual site associated with the $5 \mathrm{~S}$ principle, daily team cluster, and plan-do-checkadjust procedure [24-26].

2.3. Building Information Modeling. BIM is defined as digital representation of a facility illustrating accurate geometry and pertinent data used for supporting the project's fabrication, construction, and procurement work $[6,27]$. Building information models also encompass exchangeable data or files used to assist communication and decision making processes [28]. The term $4 \mathrm{D}$ BIM refers to adding time dimension or schedule-related information into the 3D BIM model (usually $3 \mathrm{D}$ computer-aided design or CAD) of the project [29]. With the use of simulation in 4D models, many construction conflicts, design clashes, and constructability issues can be found and resolved in advance [30]. 5D BIM is another variation of BIM models developed to incorporate the cost dimension [31]. 5D BIM is still in its infancy stage of practice, and 6D BIM, which has all data of the project's lifecycle management, is forthcoming in practice $[32,33]$. All such BIM-centric concepts are useful for any kind of project delivery method. BIM software is varied due to the complexity of its usages and types of project [27, 34]. BIM implementation in the US involves virtual design and construction (VDC) concepts and theories [35-37]. 
There are many studies about the coordination between IPD and BIM or lean construction and BIM but the particular integration of these three elements has not yet been studied. This is while many construction firms try to combine the functions of each component in order to boost the productivity of their projects [38-40]. In order to successfully integrate IPD, lean construction, and BIM, a collection of their essential conceptions and a detailed analysis of such combination are critical.

2.4. Current Studies on the Integration of IPD, Lean Construction, and BIM in Construction. The current construction literature associated with the integration of IPD, lean construction, and BIM is limited, and existing studies mostly focus on qualitative approaches. As one of the first qualitative studies related to implementing BIM in conjunction with lean principles and IPD, Miettinen and Paavola [41] conducted a position literature study outlining developments and enhancements of this cooperation. As a result, they proposed two conceptual frameworks, namely, normative and the activity-theoretical/evolutionary, where BIM can be utilized together with other management tools and project concepts. Rokooei [42] affirmed that the use of the BIM-based IPD approach supports the project team to keep track and review the project in addition to making important decisions and resolving potential conflicts to enhance the project execution. Another study showed that BIM utilization enables collaborative lean construction exercises extensively; in fact, BIM users experience leaner procedures by minimizing waste and maximizing value and are more able to deal with potentially complex conflicts and threats to project success [43]. In a theoretical approach to analyze the collaboration between IPD and BIM, Froese [44] indicated that these two elements can lead to a comprehensive scheme that establishes meaningful and predictable relationships between the time constraint, processes, and products. The aforementioned studies suggest that past efforts using qualitative analyses supports the mixed use of IPD, lean practices, and BIM in improving project performance.

In terms of quantitative approaches, the existing body of knowledge includes research focusing mostly on case studies about the feasibility of using ILB. Using a case study of the first IPD-implemented project, AutoDesk headquarters in San Francisco, California, Kent and Becerik-Gerber [7] concluded that the application of IPD in the construction industry was, at the time, in its infancy, but the utilization of BIM can assist IPD to be more productive and valuable approach. Lee et al. [45] used three real-world projects in California to assess the project performance with the simultaneous implementation of IPD, lean principles, and BIM. Furthermore, many construction professionals and experts believe that BIM application will intensively facilitate lean principles in expanding project performance [22]. Taking into account the improvement of project performance, IPD and lean construction need to be utilized together with a view to improve reliability between project participants and increase true value for everyone [46].
Correspondingly, quantitative approaches in the current construction literature reinforce the integration of IPD, lean practices, and BIM in achieving better project performance.

This research paper, first, conducted the grounded theory for the qualitative part in order to demonstrate how ILB integration can be theoretically achieved. Second, a quantitative approach with multiple statistical testing processes aiming at analyzing how ILB integration was actually implemented in vertical construction projects was proposed. Finally, key findings were summarized to support the discussion points.

\section{Research Methodology}

This study attempts to fill in the current underlying research gaps of incorporating IPD, lean principles, and BIM by utilizing both qualitative and quantitative approaches to assess ILB-based project performance. Firstly, qualitative research manner was used to gather information and case studies of ILB in the current construction industry which leads to a summary of how to use ILB and its structure. Secondly, quantitative research manner was executed with multiple statistical testing in order to assess proposed hypotheses. Lastly, a detailed discussion was performed.

3.1. Data Collection. Initially, data regarding 76 vertical construction projects with a variety of use cases, including healthcare, educational, commercial, military, and industrial, were collected via phone interviews, emails, published articles, construction firms' websites, and other online sources. Due to the nature of some projects and according to the nondisclosure agreements (NDA) between the owner and contractors, several data sources are required to be kept confidential. The phone interviews took place with participations of numerous construction professionals from 36 general contractor firms in the US. After cleaning the collected data (i.e., removing missing data points and extreme outliers), data regarding 72 projects were prepared to proceed with the qualitative and quantitative analyses. The majority of the data pertained to healthcare $(61.84 \%)$ followed by commercial (9.21\%) and educational (9.21\%) projects.

Table 1 shows descriptive statistics of collected data with 55 IPD-utilized, 70 BIM-employed, and 54 lean-based projects. Turner Construction, DPR Construction, and Clark Construction were the top three firms that provided the majority of the collected data.

3.2. Qualitative Analysis. To thoroughly understand the extent of using IPD, BIM, and lean practices in the current US construction industry, a commonly used qualitative method, called the grounded theory, was utilized. Grounded theory is a general methodology to develop theory that is grounded in the data collected systematically about the phenomena of the research [47]. In this case, the phenomenon of the research is ILB combination in order to theoretically assess ILB-based project performance. Due to the fact that there are many different types, definitions, and 
TABle 1: Descriptive statistics of collected data.

\begin{tabular}{lcccccc}
\hline Characteristics & Unit & $\mathrm{N}$ & Mean & Median & Max & Min \\
\hline $\begin{array}{l}\text { Project area } \\
\text { Planned } \\
\text { schedule }\end{array}$ & sq.ft & 72 & 389,590 & 200,000 & $4,000,000$ & 1,600 \\
$\begin{array}{l}\text { Actual } \\
\text { schedule }\end{array}$ & Month & 72 & 30 & 25 & 125 & 1 \\
$\begin{array}{l}\text { Target cost } \\
\text { Million } \\
(\$)\end{array}$ & 72 & 244 & 124 & 1,300 & 0.5 \\
$\begin{array}{l}\text { Actual cost } \\
\text { Million }\end{array}$ & 72 & 240 & 122 & 1,298 & 0.3 \\
$\begin{array}{l}\text { Year of } \\
\text { completion }\end{array}$ & Year & 72 & 2012 & 2013 & 2019 & 2007 \\
\hline
\end{tabular}

practices of IPD, BIM, or lean construction in the industry, it is difficult to classify and recognize typical practices of those three methods. The objective of the grounded theory used in this study was to identify and group all common practices of ILB in order to provide a comprehensive view of the current use of ILB in the US construction industry.

According to grounded theory analysis, collected information is initially coded by identifying and naming essential concepts, indicating main phrases, and transforming data into theoretical components. Theorized concepts are needed before preparing the first draft for data analysis. Examined theories are incorporated and refined together with generating conceptual models in order to compare analyzed data and write up complete theories [47]. In this study, qualitative data were collected via phone interviews, emails, and other online materials. Qualitative questions related to definitions, practices, current uses, and benefits of ILB were distributed to collect opinions and subjective judgements of professionals about the use of ILB in vertical construction.

3.3. Quantitative Analysis. In the quantitative analysis part, this study used the following as the null hypotheses for univariate and multivariate statistical tests:

(1) The use of all three components (IPD, BIM, and lean practices) does not statistically significantly affect the cost performance of building construction projects.

(2) The use of all three components (IPD, BIM, and lean practices) does not statistically significantly affect the schedule performance of building construction projects.

(3) The use of all three components (IPD, BIM, and lean practices) does not statistically significantly affect both cost and schedule performance of building construction projects.

In order to analyze the relationships and characteristics of ILB synergies, the descriptive statistics research method that represents the relations of collected variables was applied. Inference statistics theory, such as analysis of variance (ANOVA), generalized linear model (GLM), and data transformation techniques like power transform and natural logarithm are used in this analysis. The Statistical Package for the Social Sciences (SPSS) computer software is employed to perform the statistical testing analyses. A summary of input variables and control factors is presented in Table 2: the first model contains a full ILB integration; the second model contains lean and BIM; and the third model contains IPD and BIM.

Descriptive statistics are employed to calculate the median, mode, mean, maximum, and minimum values of the standard deviation, kurtosis, and skewness of the collected data. Subsequently, analyzed variables are examined by normality tests to determine if the collected data are normally distributed. If normal distribution is not observed, methods of data transformation including power transform, the decimal logarithm, linear transformation, natural logarithm, and inverse distribution functions are used. Afterwards, normally distributed data are classified into three separate models according to Table 1 and analyzed by univariate and multivariate analysis of variance (ANOVA) as well as Duncan's multiple range test (MRT). Duncan's MRT is a multiple comparison process which utilizes an estimating range statistic in order to measure groups of means. The outcomes of these tests demonstrate accurate, detailed, and certain differences of cost performance and schedule performance of analyzed groups in terms of the mean, median, and mode. About thirty projects are grouped for each model based on their characteristics of delivered by IPD, enhanced lean principles, and utilized BIM techniques. Multiple ANOVA tests are carried out to assess the proposed hypotheses while the least square regression is performed by the applying generalized linear models (GLMs). The use of GLM is to assure the reliability of quantitative data in the analytical process.

\section{Grounded Theory Implementation}

Grounded theory in this study is used to demonstrate ILB cooperation and their effects in enhancing project performance. According to Khan [47], grounded theory analysis includes four main steps as follows:

(i) Stage 1-codes: determining key data and required aspects in order to obtain facts and specific information.

(ii) Stage 2-concepts: clarifying and grouping collected data by considering analogous and mutual concepts.

(iii) Stage 3-categories: developing theories and conceptual models based on immense groups of defined concepts.

(iv) Stage 4-theory: revealing and expounding developed descriptions and concepts in furtherance of making clear study objections.

The first step of this research is to conduct an adequate review of the literature and collect key data related to IPD, lean construction, and BIM use in both synergistic and individual perspectives. The used keywords were "Integrated Project Delivery," "Building Information Modeling," and "Lean practices in construction." In stage 1, a literature review was conducted to determine the IPD-related 
TABLe 2: Analyzing models and control factors.

\begin{tabular}{lccccc}
\hline Model & \multicolumn{3}{c}{ Variables } & \multicolumn{2}{c}{ Control factors } \\
& IPD & Lean & BIM & $\begin{array}{c}\text { Cost } \\
\text { performance }\end{array}$ & $\begin{array}{c}\text { Schedule } \\
\text { performance }\end{array}$ \\
\hline 1 & Y & Y & Y & C1 & S1 \\
2 & - & Y & Y & C2 & S2 \\
3 & Y & - & Y & C3 & S4 \\
\hline
\end{tabular}

concepts, lean practices, and BIM-related themes which were later transferred to stage 2 . In stage 2 , fourteen concepts associated with the incorporating use of IPD, lean construction, and BIM were gathered from literature reviews, interviews, and online materials and summarized in Table 3. These concepts are the key practices of ILB in the construction industry which certainly impact on the success of implementation of ILB. The lean culture and associated techniques provide state-of-the-art principles of typical lean practices in construction.

After gathering and organizing all ILB-associated data, the analyzed definitions and perceptions were input into a conceptual model that consists of overlaps and commonalities of IPD, lean principles, and BIM using mind-mapping and pattern-matching techniques. This model includes fourteen particular concepts investigated in the earlier section and is constituted into six prime measures used to explain how to enhance project performance with the fourteen conceptual practices of ILB indicated in Table 3. In consideration of clarifying the relationships of every prime measure within the model, the categories' selection (stage 3) and arrangement of collected concepts are demonstrated as follows:

(i) Durable value and continuous development: (1) BIM-4D and BIM-5D; (3) key performance indicators (KPIs); (4) A3 report; (6) project modification or innovation (PMI); (7) value stream mapping and cluster teams; (9) multiparty agreement (MPA); (11) virtual design and construction (VDC); (13) lean culture and other techniques; and (12) set-based design (SBD).

(ii) Customer satisfaction and waste elimination: (1) BIM-4D and BIM-5D; (4) A3 reports; (5) choosing by advantages (CBA); (6) project modification or innovation (PMI); (7) value stream mapping (VSM); (8) last planner system; (9) multiparty agreement (MPA); (10) target value design (TVD); (11) virtual design and construction (VDC); (12) set-based design (SBD); (13) lean culture; and (14) owner participation.

(iii) Communication and achievement metrics: (4) A3 Reports; (5) choosing by advantages (CBA); (6) project modification or innovation (PMI); (7) value stream mapping; (8) last planner system; (9) multiparty agreement (MPA); (11) virtual design and construction (VDC); and (14) owner participation.

(iv) Interrelationship improvement: (2) big room; (4) A3 reports; (5) choosing by advantages (CBA); (6) project modification or innovation (PMI); (8) last planner system; (9) multiparty agreement (MPA); (10) target value design (TVD); and (13) lean culture.

(v) Information transmission and transparency: (3) key performance indicators (KPIs); (4) A3 reports; (5) choosing by advantages (CBA); (7) value stream mapping; (8) last planner system; (9) multiparty agreement (MPA); (11) virtual design and construction (VDC); and (13) lean culture.

(vi) True cooperation and trusts: (2) big room; (6) project modification or innovation (PMI); (7) value stream mapping; (8) last planner system; and (9) multiparty agreement (MPA).

Stage 4 of the grounded theory will be verified through a quantitative approach with descriptive statistics and inferential testing of cost and schedule performances in the next section.

\section{Quantitative Data Analysis}

5.1. Descriptive Statistics Analysis and Data Normality. The particular descriptive statistics of cost performance and schedule performance used in this paper are means, variance, range, standard deviation, and median. In addition, the normality test was performed as a requirement of assumptions for inference statistics (hypothesis testing) to confirm whether the data are normally distributed or have some degree of symmetry. The skewness test for cost performance returned the value of -7.212 and that of the schedule performance was 2.080. Since neither of the skewness values are in the range of -1 to 1 , this distribution is not normal. In addition, the Kolmogorov-Smirnov (K-S) test was used to further verify that the data are not following the normal distribution. The normality Shapiro-Wilk test confirmed that the data pertaining to the two factors are not normally or near-normally distributed. Therefore, data transformation was required to convert and reconstruct the datasets for further statistical analyses.

5.2. Data Transformation and Inferential Statistics Procedure. A two-step mean transformation method was used for converting the continuous variables to the ones normally distributed. The process begins with fractionally ranking variable cases in order to have a consistency for the transformed variable [48]. Subsequently, the inverse normal distribution was employed to transform data distribution with the SPSS software. As a result, the skewness distributions of both cost performance and schedule performance data are adjusted, to satisfy the requirements of normality, uniformity, and linearity of multiple analyzed variances. In addition to the cost performance and schedule performance data transformation, project size (or gross area) was also transformed to be included in the univariate and multivariate ANOVA analyses as well as generalizing linear models in the next step of the data analysis procedure. As a result, the new skewness test statistics for cost performance 
TABLE 3: Synergizing concepts from case studies.

Key analyzing concepts

(1) BIM-4D and 5D with five different levels: visualization, coordination, constructability, fabrication/installation and total cost of ownership

(2) A big room, co-location, small breaks, and track plan percent complete (PPC)

(3) Key performance indicators (KPIs)

(4) A3 reports or rainbow report

(5) Choosing by advantages (CBA)

(6) Project modification or innovation (PMI)

(7) Value stream mapping and cluster teams

(8) The last planner system (e.g., pull planning, master scheduling, weekly work planning, etc.)

(9) Multiparty agreement (MPA) (Consensus-DOCS 300-2008, AIA document A195-2008, A295-2008, B195-2008) and single purpose entity (SPE) (AIA document C195-2008)

(10) Target value design (TVD)

(11) Virtual design and construction (VDC)

(12) Set-based design (SBD)

(13) Lean culture and other techniques (i.e., the "customer-supplier" viewpoint, plan do study act (PDSA), etc.)

(14) Owner participation in ILB

and schedule performance after transformation were 0.03 and 0.06 , respectively, which are in the acceptable range of normal and near-normal distribution (i.e., between -1 and 1).

5.3. Measurements of Project Performance Metrics. The use of any project delivery methods, tools, or techniques can be measured by proper project performance in order to adequately assess their efficiency and precisely enhance them. This study utilizes two commonly used measurements for construction projects: cost and schedule performance, which are calculated using the following equation:

$$
\begin{aligned}
& \mathrm{CP}=\frac{(\mathrm{FC}-\mathrm{IC}) \times 100}{\mathrm{IC}}, \\
& \mathrm{SP}=\frac{(\mathrm{FD}-\mathrm{PD}) \times 100}{\mathrm{PD}},
\end{aligned}
$$

where $\mathrm{CP}$ is the cost performance, $\mathrm{FC}$ is the final project cost, IC is the initial project cost, SP is the schedule performance, FD is the final duration, and PD is the planned duration. The following section provides descriptive statistics and treatments for nonnormally distributed data of cost performance and schedule performance.

5.4. Cost Performance Analysis. To evaluate the first null hypothesis, adjusted cost performance data as the dependent variable, the five levels of ILB combination as the independent variables, and the adjusted project size as the covariate factor were used for the univariate and multivariate ANOVA tests. With the $p$ value of 0.63 at $95 \%$ confidence interval, there was no statistically significant difference between cost performances of the different models. Because of the small sample size, the use of several post hoc tests, including Hochberg's GT2 and Games-Howell process is recommended by Dell et al. [49] to ensure equality of population variances. This setting was applied to the rest of univariate tests. The multiple comparison range tests based on the confidence interval of $95 \%$ and examination via two procedures with cost performance dependent variable are shown in Table 4. In particular, the table shows the differences between one combination and the other at $95 \%$ confidence interval. In addition, it also indicates the significance of each difference to show the reliability of the comparison. However, there was no statistically significant difference found in pairwise comparisons for combination groups.

According to the results from estimated marginal means and significance ( $p$ values), the reliability of the outcomes of the comparison between five combination levels with the cost performance index variable was ensured. As a result, the first null hypothesis is rejected because of the insignificance or $p$ value higher than 0.05 in the univariate test. Notwithstanding the null hypothesis evaluation for cost performance, different projects benefiting from different combinations of IPD, lean construction, and BIM showed interesting results in terms of the cost performance mean. Results of the ANOVA test with the 95\% confidence interval for cost performance (with the adjustment for project sizes) indicate that projects that utilize IPD, lean construction, and BIM have the highest value of cost performance compared to other projects.

5.5. Schedule Performance Analysis. In order to evaluate the second null hypothesis, the univariate test for the ILB effects on schedule performance was conducted with SPSS software. Here, adjusted schedule performance data are used as the dependent variables, the five levels of ILB combination serve as the independent variables, and the adjusted project size is used as the covariate factor for the ANOVA tests. In consideration of investigating the differences in schedule performance of five levels, multiple comparison range tests were carried out. Similar to the cost performance's univariate results, a full ILB combination shows a significant mean difference compared to the others which proves that its implementation would have a positive effect on the project's schedule performance as shown in Table 5 . The $p$ value (0.008) of this univariate analysis indicates that the null 
TABLE 4: Pairwise comparisons of combination groups in terms of cost performance.

\begin{tabular}{lccc}
\hline Combination group & & Mean difference & Significance $(p$ value $)$ \\
\hline \multirow{2}{*}{ IPD + Lean + BIM (ILB) } & Lean + BIM & 0.045 & 0.909 \\
\hline \multirow{2}{*}{ Lean + BIM } & IPD + BIM & 0.031 & 0.902 \\
\hline \multirow{2}{*}{ IPD + BIM } & ILB & -0.048 & 0.640 \\
& IPD + BIM & -0.017 & 0.992 \\
\hline
\end{tabular}

TABle 5: Pairwise comparisons of combination groups in terms of schedule performance.

\begin{tabular}{lccc}
\hline Combination group & & Mean difference & Significance $(p$ value $)$ \\
\hline \multirow{2}{*}{ IPD + Lean + BIM (ILB) } & Lean + BIM & 0.008 & 0.997 \\
& IPD + BIM & 0.058 & 0.081 \\
\multirow{2}{*}{ Lean + BIM } & ILB & -0.008 & 0.997 \\
& IPD + BIM & 0.050 & 0.271 \\
\multirow{2}{*}{ IPD + BIM } & ILB & -0.058 & 0.081 \\
& Lean + BIM & -0.050 & 0.271 \\
\hline
\end{tabular}

hypothesis of the significant effect of ILB combination on project schedule performance cannot be rejected. Pairwise comparisons of combination groups in terms of schedule performance do not show significant difference except when the full ILB combination is compared to using only BIM.

As compared the schedule performance values for the projects that used different combinations of ILB components to those of the projects that only employed BIM, full combination of ILB components indicates the highest schedule performance value while using only BIM results in the lowest schedule performance value of all the models.

5.6. Cost and Schedule Performance Analysis. The third null hypothesis is investigated to assess the impact of ILB integration on both cost and schedule performances simultaneously with normalization with respect to the size of projects. As such, a multivariate ANOVA (or MANOVA) test is performed. F-ratio and four measuring statistics, namely, Pillai's trace, Hotelling-Lawley's trace, Wilk's lambda, and Roy's largest root, have been used to test the null hypothesis. These four tests were used in order to ensure the reliability of the multivariate test regarding the statistically significant difference between the three separate models, including ILB, Lean-BIM, and IPD-BIM, in terms of cost performance and schedule performance. Table 6 summarizes the results of the MANOVA test. In particular in this table, values refer to the test statistics of the four models; the F-ratio shows the test reliability; the significance refers to the acceptance/rejection of the research hypothesis, and observed power is another variable which confirms that the results are reliable. According to four distinguishing multivariate tests, $p$ values from 0.005 to 0.03 , which are less than 0.05 , the third null hypothesis is answered, so a full combination of IPD, lean construction, and BIM will have a significant effect on both cost and schedule performance, considered as a group, with differences in project sizes or gross area. In addition, the $F$ value and hypothesis df show
TABle 6: Multivariate tests.

\begin{tabular}{lccccc}
\hline Variable & Test model & Value & $F$ & Sig. & $\begin{array}{c}\text { Observed } \\
\text { power }\end{array}$ \\
\hline \multirow{4}{*}{ ILB } & Pillai's trace & 0.219 & 2.156 & 0.034 & 0.838 \\
& Wilks' lambda & 0.787 & 2.199 & 0.031 & 0.847 \\
& $\begin{array}{c}\text { Hotelling's trace } \\
\text { Roy's largest } \\
\text { root }\end{array}$ & 0.264 & 2.241 & 0.028 & 0.854 \\
\hline
\end{tabular}

the reliability of these hypothetical tests (Table 6). In particular, the third hypothesis is accepted because of the multivariate result of a full ILB in terms of both cost performance and schedule performance by four statistical tests: Pillai's Trace, Wilks' Lambda, Hotelling's Trace, and Roy's largest root. As a result, a full ILB does have a significant effect on both cost performance and schedule performance of construction projects.

\section{Discussion and Conclusion}

In this research, 72 real-world construction projects that implemented a subset of IPD, lean principles, and BIM (ILB in short) were studied. Qualitative analysis was performed to identify specific concepts that lead to a successful implementation of ILB using grounded theory. Additionally, six influential aspects of a successful project were outlined in terms of quality, cost, and schedule performance. Developed with a combination of defined concepts and project-specific factors, an ILB checklist was created with supporting evidence. According to that recommended checklist for ILB synergies, unique tools and techniques are summarized and categorized into three key sections related to four main phases of a typical construction project. This classification helps project team members to consider and employ essential factors leading to project success with respect to the leveraging the power of ILB. The cooperative characteristics of the fourteen identified concepts are evaluated during 
different phases of a construction project, from planning to operation.

In terms of quantitative analysis, descriptive statistics were used to evaluate the effect of ILB integrations on projects' cost performance and schedule performance. Various quantitative and inferential statistics tests were performed, including normality examination, data transformation, and univariate and multivariate ANOVA investigation. According to analyzed outcomes, for projects that implement a full combination of ILB, (1) the effect on the cost performance index was not statistically significant, (2) the effect on the schedule performance index was statistically significant, and (3) the effect on the cost performance index and schedule performance index, collectively, was statistically significant.

This study contributes to the body of knowledge in the general area of construction engineering and management by providing evidence-based indicators of the factors affecting successful implementation of IPD, lean principles, and BIM. With the identification of 14 most common practices of using ILB in the current US construction industry, this study contributes to the body of knowledge by providing contextual information about having all the three components together. This study also contributed to the body of practice by providing an insight about the cost and schedule performance of projects that took advantage of ILB. It also demonstrates the significance of implementing those typical three factors on the cost and schedule performance of the projects using vertical project cases. Future research may evaluate other project performance measures such as the number of request of information (RFI), punch list ratio, and green features implementation. Moreover, future studies can provide designated analysis for different industry sectors such as commercial, residential, and industrial, in separate categories.

\section{Data Availability}

The data used to support the findings of this study are available from the corresponding author upon request.

\section{Disclosure}

Any opinions, findings, conclusions, and recommendations expressed in this paper are those of the authors and do not necessarily represent those of the ORSP.

\section{Conflicts of Interest}

The authors declare that there are no conflicts of interest regarding the publication of this paper.

\section{Acknowledgments}

The presented work was partially funded by the California State University East Bay (CSUEB) Office of Research and Sponsored Programs (ORSP) Faculty Support Grant (FSG). The authors gratefully acknowledge the support from the ORSP.

\section{References}

[1] K. McCook, Dodge Data and Analytics: 2015-16 Outlook for, U.S. Construction Presentation, Dodge, Auburn Hills, MI, USA, 2015.

[2] C. Gray and E. Larson, Project Management, McGraw-Hill/ Irwin, Boston, MA, USA, 5th edition, 2011.

[3] F. Castronovo, B. Awad, and R. Akhavian, "Implementation of virtual design reviews in the generation of as-built information," Construction Research Congress (CRC), 2018.

[4] R. Akhavian and A. Behzadan, "Simulation-based evaluation of fuel consumption in heavy construction projects by monitoring equipment idle times," in Proceedings of the 2013 Winter Simulations Conference (WSC), IEEE, Washington, DC, USA, December 2013.

[5] R. Akhavian and A. Behzadan, "Wearable sensor-based activity recognition for data-driven simulation of construction workers' activities," in Proceedings of the 2015 Winter Simulations Conference (WSC), IEEE, Huntington Beach, CA, USA, December 2015.

[6] N. Dong, A. Khanzode, and H. Lindberg, "Applying lean principles, BIM, and quality control to a construction supply chain management system," in Proceedings of the 30th CIB W78 International Conference, Beijing, China, 2013.

[7] D. C. Kent and B. Becerik-Gerber, "Understanding construction industry experience and attitudes toward integrated project delivery," Journal of Construction Engineering and Management, vol. 136, no. 8, pp. 815-825, 2010.

[8] I. Tommelein, "Journey toward lean construction: pursuing a paradigm shift in the AEC industry," Journal of Construction Engineering and Management, vol. 141, no. 6, article 04015005, 2015.

[9] AIA, Integrated Project Delivery: Case Studies, AIA, Hong Kong, China, 2010, http://info.aia.org/aia/ipdcasestudies.cfm.

[10] I. H. El-adaway, "Integrated project delivery case study: guidelines for drafting partnering contract," Journal of Legal Affairs and Dispute Resolution in Engineering and Construction, vol. 2, no. 4, pp. 248-254, 2010.

[11] O. Matthews and G. Howell, "Integrated project delivery an example of relational contracting," Lean Construction Journal, vol. 2, no. 1, pp. 46-61, 2005.

[12] R. Ghassemi and B. Becerik-Gerber, "Transitioning to integrated project delivery: potential barriers and lessons learned," Lean Construction Journal, pp. 32-52, 2011.

[13] G. Ballard and G. Howell, "What kind of production is construction," in Proceedings of the 6th International Conference on Lean Construction, Guaruja, Brazil, 1998.

[14] L. Koskela, An Exploration Towards a Production Theory and its Application to Construction, VVT Technical Research Centre of Finland, Espoo, Finland, 2000.

[15] L. Koskela, G. Howell, G. Ballard, and I. Tommelein, "The foundations of Lean construction," in Design and Construction: Building in Value, R. Best and G. de Valence, Eds., Elsevier, Amsterdam, Netherlands, In press, 2002.

[16] L. Forbes, S. Ahmed, and D. Batie, "Incorporating lean in CM education to improve the construction industry-proposing a model," in Proceedings of the 50th ASC Annual International Conference, Associated Schools of Construction, Washington, DC, USA, March 2014.

[17] L. Forbes and S. Ahmed, Modern Construction: Lean Project Delivery and Integrated Practices, CRC Press, Boca Raton, FL, USA, 2011.

[18] L. Koskela, A. Ferrantelli, J. Niiranen, E. Pikas, and B. Dave, "Epistemological explanation of lean construction," Journal of 
Construction Engineering and Management, vol. 145, no. 2, article 04018131, 2019.

[19] R. Sacks, "Modern construction: lean project delivery and integrated practices," Construction Management and Economics, vol. 31, no. 4, pp. 394-396, 2013.

[20] G. Howell and L. Koskela, "Reforming project management: the role of lean construction," in Proceedings of the 8th Annual Conference of the International Group for Lean Construction, Brighton, UK, July 2000.

[21] R. Sacks, B. Dave, L. Koskela, and R. Owen, "Analysis framework for the interaction between lean construction and building information modeling," in Proceedings for the 17th Annual Conference of the International Group for Lean Construction, Taipei, Taiwan, July 2009.

[22] R. Sacks, L. Koskela, B. A. Dave, and R. Owen, "Interaction of lean and building information modeling in construction," Journal of Construction Engineering and Management, vol. 136, no. 9, pp. 968-980, 2010.

[23] H. G. Ballard, The Last Planner System of Production Control, School of Civil Engineering, Faculty of Engineering, The University of Birmingham, Birmingham, UK, 2000.

[24] R. Jugulum and P. Samuel, Design for Lean Six Sigma, John Wiley and Sons, Hoboken, NJ, USA, 2008.

[25] A. Khanzode, M. Fischer, and D. Reed, "Case study of the implementation of the lean project delivery system (LPDS) using virtual building technologies on a large healthcare project," in Proceedings of the IGLC-13, Sydney, Australia, July 2005.

[26] F. Bamana, N. Lehoux, and C. Cloutier, "Simulation of a construction project: assessing impact of just-in-time and lean principles," Journal of Construction Engineering and Management, vol. 145, no. 5, article 05019005, 2019.

[27] D. Gerber, B. Becerik-Gerber, and A. Kunz, "Building information modeling and lean construction: technology, methodology and advances from practice," in Proceedings of the 18th Annual Conference, International Group for Lean Construction, Haifa, Israel, July 2010.

[28] B. Succar, W. Sher, and A. Williams, "Measuring BIM performance: five metrics," Architectural Engineering and Design Management, vol. 8, no. 2, pp. 120-142, 2012.

[29] Y. Jung and M. Joo, "Building information modelling (BIM) framework for practical implementation," Automation in Construction, vol. 20, no. 2, pp. 126-133, 2011.

[30] U. Umar, N. Shafiq, A. Malakahmad et al., "4D BIM application in AEC industry: impact on integrated project delivery," Research Journal of Applied Sciences, Engineering and Technology, vol. 10, no. 5, pp. 547-552, 2015.

[31] H. Fong, BIM Development-Hong Kong and World Wide Trend, Autodesk, Wuhan, China, 2009.

[32] S. Azhar, "Building information modeling (BIM): trends, benefits, risks, and challenges for the AEC industry," Leadership and Management in Engineering, vol. 11, no. 3, pp. 241-252, 2011.

[33] C. Eastman, P. Teicholz, R. Sacks, and K. Liston, BIM Handbook: A Guide to Building Information Modeling for Owners, Managers, Designers, Engineers and Contractors, John Wiley and Sons Inc., Hoboken, NJ, USA, 2nd edition, 2012.

[34] S. Liu, B. Xie, L. Tivendal, and C. Liu, "Critical barriers to BIM implementation in the AEC industry," International Journal of Marketing Studies, vol. 7, no. 6, p. 162, 2015.

[35] A. Khanzode, M. Fischer, and D. Reed, "Benefits and lessons learned of implementing building virtual design and construction (VDC) technologies for coordination of mechanical, electrical, and plumbing (MEP) systems on a large healthcare project," Itcon, vol. 13, pp. 324-342, 2008.
[36] A. Khanzode, M. Fischer, D. Reed, and G. Ballard, "A guide to applying the principles of virtual design and construction (VDC) to the lean project delivery process," in Proceedings of the CIFE Working Paper \#093, Center for Integrated Facility Engineering (CIFE), Stanford, CA, USA, December 2006.

[37] V. Popov, V. Juocevicius, D. Migilinskas, L. Ustinovichius, and S. Mikalauskas, "The use of a virtual building design and construction model for developing an effective project concept in 5D environment," Automation in Construction, vol. 19, no. 3, pp. 357-367, 2010.

[38] Z. Hunzeker and D. Selezan, BIM to the MAX: Applying Lean Construction to IPD Projects Presentation, Autodesk University, San Francisco, CA, USA, 2015.

[39] B. Hyatt, "A case study in integrating lean, green, BIM into an undergraduate construction management scheduling," in Proceedings of the 47th ASC Annual International Conference, Associated Schools of Construction, Fresno, CA, USA, 2011.

[40] M. Moghadam, A. Alwisy, and M. Al-Hussein, "Integrated BIM/lean base production line schedule model for modular construction manufacturing," Construction Research Congress, pp. 1271-1280, 2012.

[41] R. Miettinen and S. Paavola, "Beyond the BIM utopia: approaches to the development and implementation of building information modeling," Automation in Construction, vol. 43, pp. 84-91, 2014.

[42] S. Rokooei, "Building information modeling in project management: necessities, challenges and outcomes," Procedia-Social and Behavioral Sciences, vol. 210, pp. 87-95, 2015.

[43] I. Kjartansdóttir, "BIM adoption in iceland and its relation to lean construction," M.S. thesis, Reykjavík University, Reykjavik, Iceland, 2011.

[44] T. M. Froese, "The impact of emerging information technology on project management for construction," Automation in Construction, vol. 19, no. 5, pp. 531-538, 2010.

[45] H. W. Lee, H. Oh, Y. Kim, and K. Choi, "Quantitative analysis of warnings in building information modeling (BIM)," $A u$ tomation in Construction, vol. 51, pp. 23-31, 2015.

[46] J. Darrington and W. Lichtig, "Integrated project delivery: aligning project organization, operating system and commercial terms," 2018, https://www.dpr.com/assets/case-studies/ IPD-Whitepaper_2018-2.pdf.

[47] S. Khan, "Qualitative research method: grounded theory," International Journal of Business and Management, vol. 9, no. 11, 2014.

[48] G. F. Templeton, "A two-step approach for transforming continuous variables to normal: implications and recommendations for IS research," Communications of the Association for Information Systems, vol. 28, no. 4, 2011.

[49] R. Dell, S. Holleran, and R. Ramakrishnan, "Sample size determination," Institute for Laboratory Animal Research Journal, vol. 43, no. 4, pp. 207-213, 2002. 


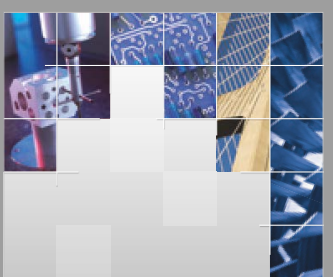

\section{Enfincering}
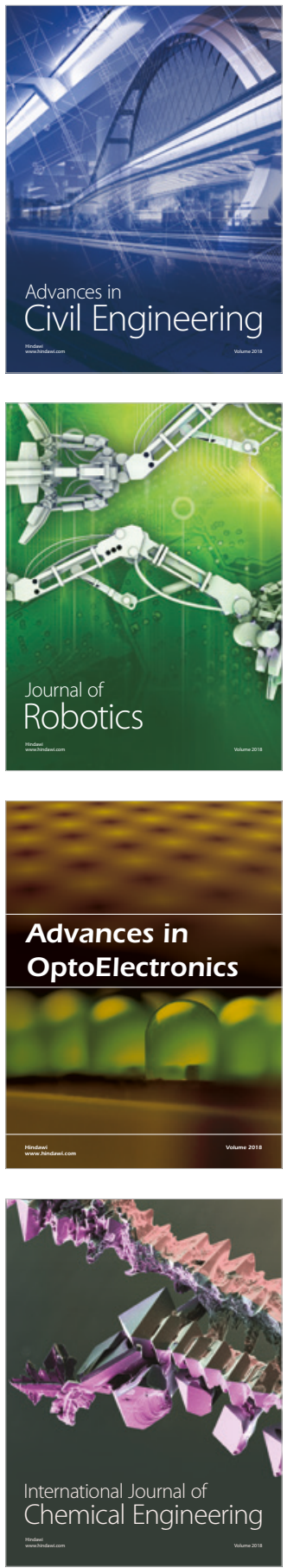

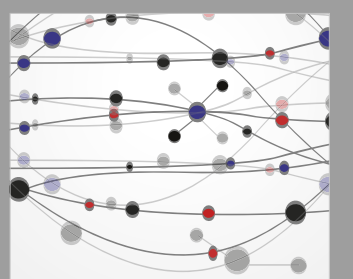

\section{Rotating \\ Machinery}

The Scientific World Journal

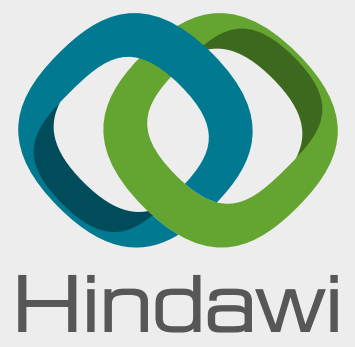

Submit your manuscripts at

www.hindawi.com
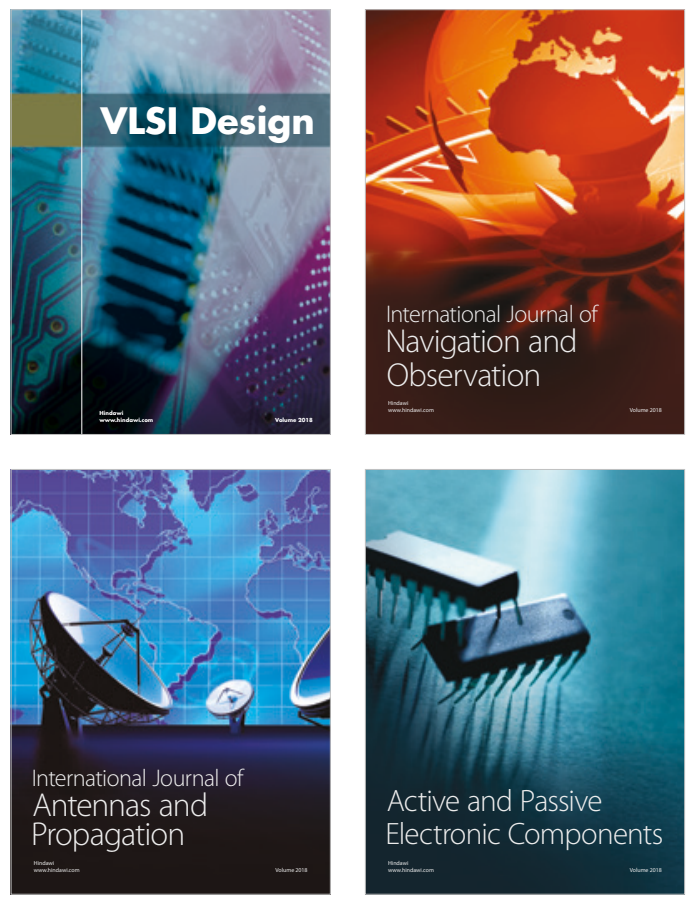
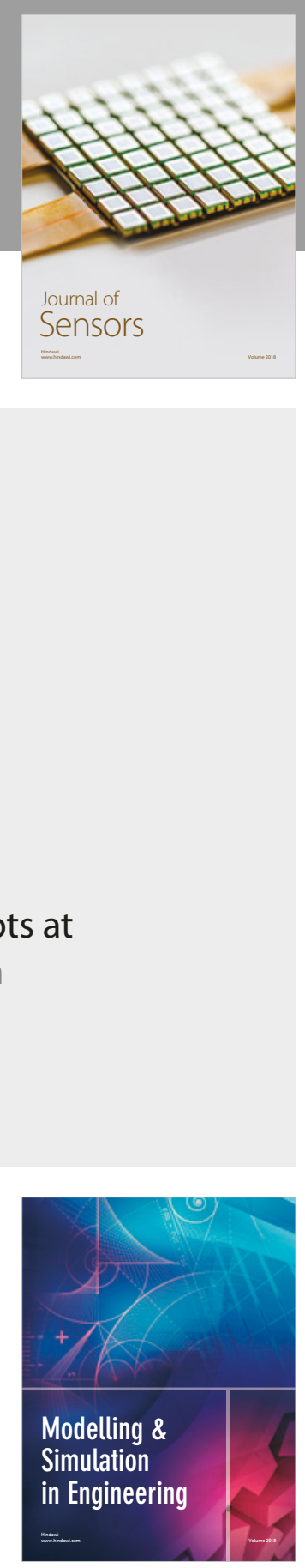

\section{Advances \\ Multimedia}
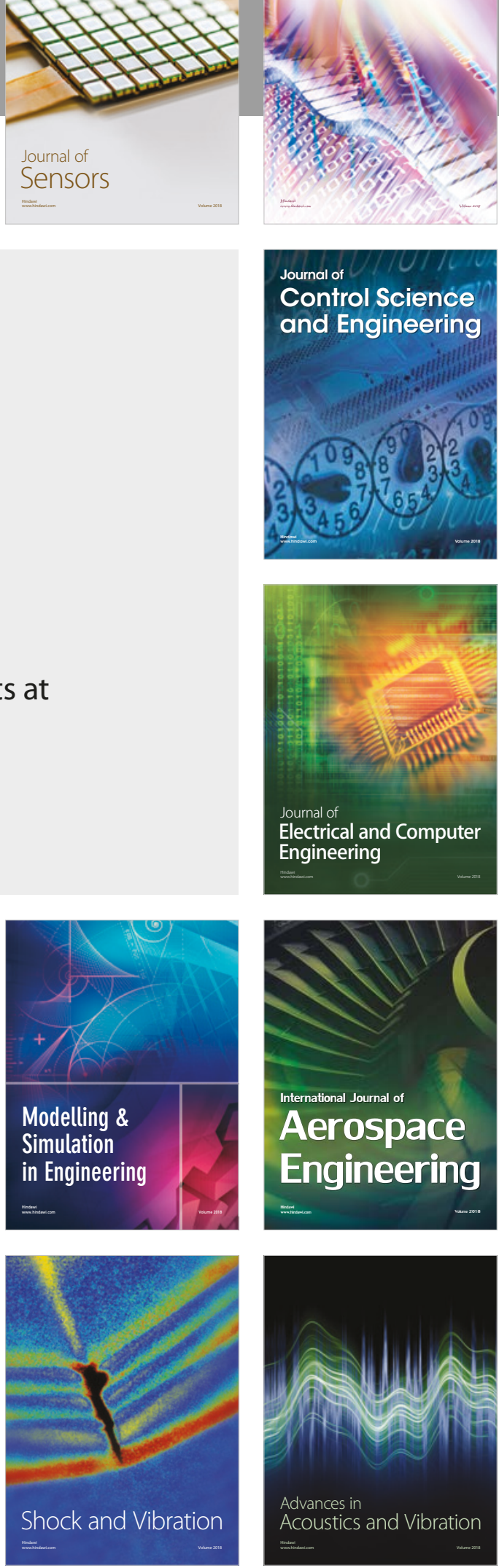